\section{Function and dysfunction of fatty acid mobilization: a review}

\author{
Joslyn K. Beard, ${ }^{1}$ J. Travis Mulliniks, ${ }^{2}$ Dustin T. Yates ${ }^{1,3 *}$
}

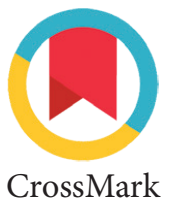

CrossMark
*Correspondence to: Dustin T. Yates, Department of Animal Science, University of Nebraska-Lincoln, Lincoln 68583 dustin.yates@unl.edu

Cite This Article: Beard, J.K., Mulliniks, J. T., Yates, D.T. 2019. Function and dysfunction of fatty acid mobilization: a review. Diabesity 5(1): 1-5. DOI: 10.15562/ diabesity.2019.53

\title{
ABSTRACT
}

Western populations have a growing obesity epidemic due in part to excessive nutrient intake from high-fat diets, which are increasingly common. Overindulgence of nutrients is associated with a greater incidence of metabolic dysfunction and a greater risk for obesity, diabetes, hypertension, and other metabolic disorders that lower quality of life. Research in humans and animal models has improved our understanding of how excess circulating free fatty acids negatively impact the ability of muscle and other tissues to regulate nutrient

\section{INTRODUCTION}

Epidemiological studies have identified metabolic disorders and heart disease as health consequences resulting from obesity in US and global populations. ${ }^{1}$ Greater accumulation of adipose tissue is associated with physiological pathologies such as hyperlipidemia, chronic inflammation, and insulin resistance. ${ }^{2}$ A primary factor in these metabolic pathologies is elevated circulating free fatty acids (FFA), which is a common characteristic of obese individuals and type 2 diabetics. ${ }^{2}$ High blood FFA concentrations lead to reduced whole-body glucose uptake and oxidation rates and also decrease skeletal muscle glycogen synthase. ${ }^{3}$ However, fatty acids are also important components of complex lipids that are necessary for structural and functional integrity of cellular membranes. Due to the cytotoxic nature of FFA, ${ }^{4}$ lipolytic enzymes tightly regulate mobilization of fatty acids from triglycerides stored within adipose tissue. ${ }^{4}$ Consequently, enzymatic dysfunction contributes to pathologies underlying the development of obesity and insulin resistance, although metabolic factors, genetics, and environment also play roles. ${ }^{5,6}$ Prolonged periods of elevated circulating FFA concentrations lead to impaired hepatic lipoprotein production, poor insulin responsiveness in skeletal muscle and liver, and pancreatic $\beta$-cell dysfunction independent of body composition. ${ }^{7}$ Recent studies have further characterized FFA-induced pathologies by identifying receptors and signaling pathways involved in the underlying mechanisms, ${ }^{8,9}$ as detailed in later sections. This fundamental research has increased our understanding of the role of high circulating uptake and utilization. It is generally accepted by the scientific community that excess circulating fatty acids lead to insulin resistance, but there is little clarity regarding the underlying mechanisms. In the present review, we will outline the current understanding of the characteristics associated with fatty acid mobilization and fatty acid utilization within specific tissues. We will also discuss the potential mechanistic role of hyperlipidemia on metabolic dysfunction associated with type 2 diabetes.

FFA in pathologies associated with obesity and type 2 diabetes. In this review, we describe the mechanisms by which disruption of fatty acid mobilization, skeletal muscle fatty acid utilization, and FFA homeostasis result in metabolic pathologies and disorders that reduce life span and lower quality of life.

\section{MECHANISM OF FATTY ACID MOBILIZATION}

In mammals, excess energy substrates are stored as triglycerides in adipose tissue and can be mobilized to maintain a balance of stored and circulating lipid concentrations. ${ }^{5}$ Storage, synthesis, and utilization of adipose triglycerides is regulated by hormonal and paracrine factors in response to changing blood FFA concentrations. ${ }^{5}$ Circulating FFA concentrations are determined by the rate at which they are mobilized and enter circulation combined with the rate at which they are cleared and deposited into adipose tissue, as illustrated in Figure 1. Fatty acid mobilization typically increases when the body enters into a hypoglycemic state due to fasting or an increase in adrenergic stimulation. ${ }^{10}$ Catecholamines from the sympathetic nervous system or the adrenal medulla are the primary stimulants of fatty acid mobilization, especially in response to stress conditions. ${ }^{10}$ Catecholamines directly affect fat cells via $G$ protein-coupled receptors. Binding of $\beta$ or $\alpha_{2}$ adrenergic receptors on adipocytes activates the signaling cascades illustrated in Figure 2 that stimulate adenylate cyclase-mediated increases in cyclic adenosine 3, 5-monophosphate (cAMP) 


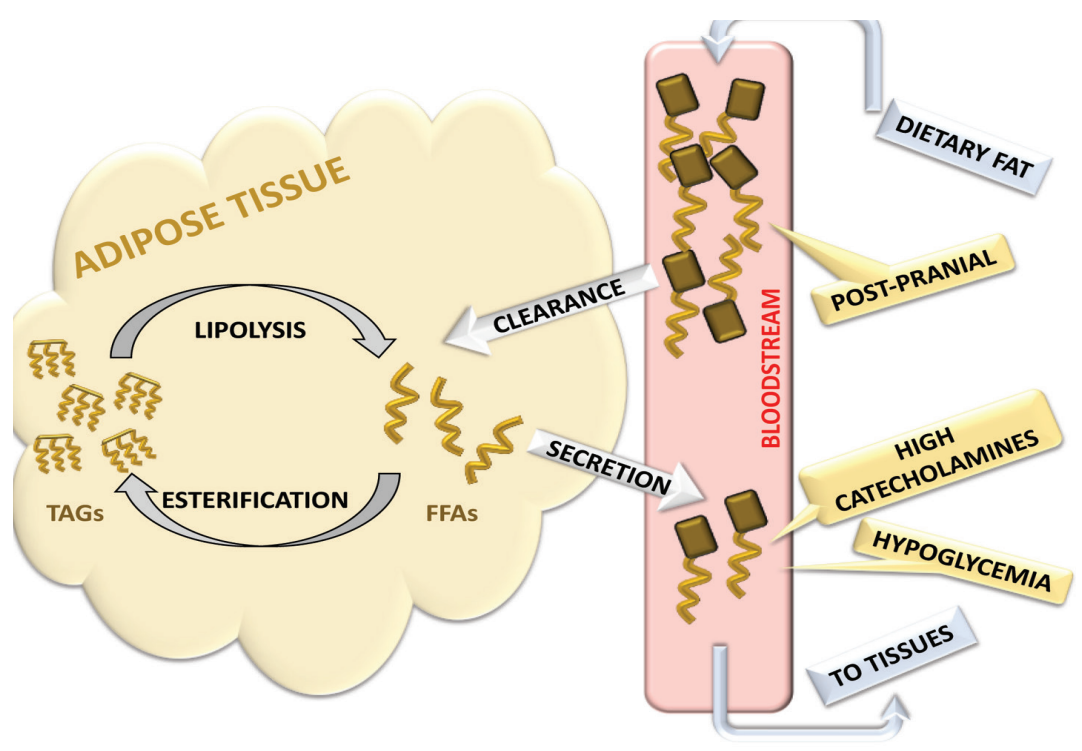

Figure 1 Concentrations of free fatty acids (FFA) in the bloodstream are determined by the combined rates at which they are mobilized / secreted into circulation and cleared from circulation.

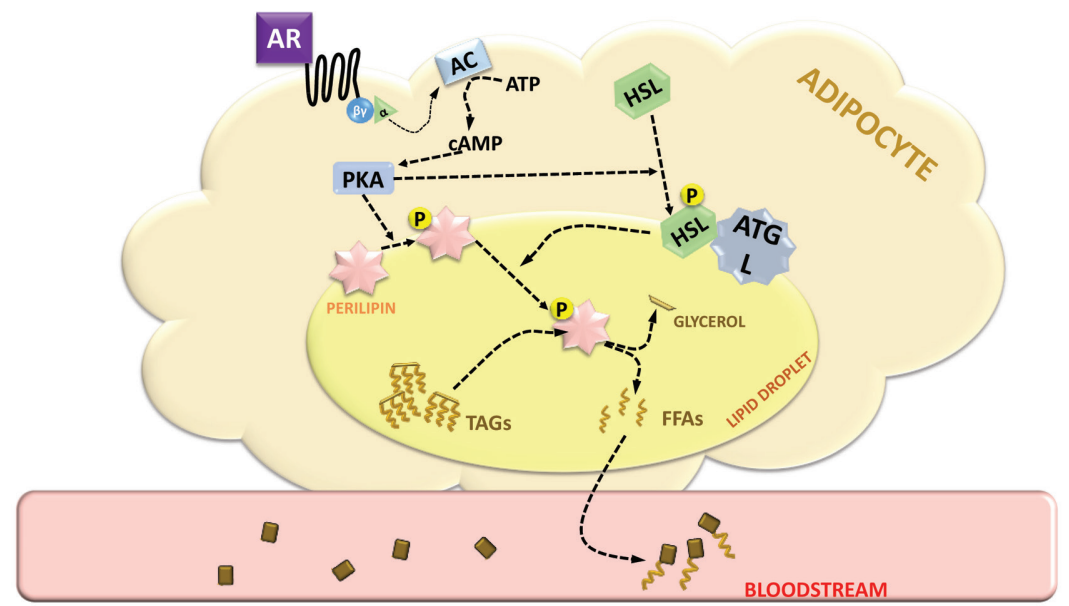

Figure 2 Catecholamines stimulate fatty acid mobilization from adipocytes. Binding of $\beta$ or $\alpha_{2}$ adrenergic $G$ protein-coupled receptors activates second messenger signal cascades that include adenylate cyclase-mediated increases in cyclic adenosine 3, 5-monophosphate (cAMP), activated cAMP-dependent protein kinase A (PKA), phosphorylated hormone sensitive lipase (HSL), and ultimately catabolized triglycerides. Adipose triglyceride lipase (ATGL) and HSL facilitate hydrolysis of triglycerides, and Perilipin A mediates FFA secretion. FFA travel in circulation bound to carrier proteins.

which in turn activates cAMP-dependent protein kinase A (PKA). ${ }^{5,7,11}$ Active PKA phosphorylates hormone sensitive lipase (HSL) that then catabolizes triglycerides stored within the adipocyte. ${ }^{7,12}$ In the cytosol, adipose triglyceride lipase (ATGL) and HSL adhere to lipid droplets to facilitate hydrolysis of triglycerides. ${ }^{13}$ Perilipin A, a structural protein located on the surface of lipid droplets, then mediates the release of fatty acids into circulation. ${ }^{5,7,12}$
Excessive fatty acid accumulation can be cytotoxic and therefore uptake and storage of fatty acids is tightly regulated. ${ }^{7,12}$ Once fatty acids are inside the cell, cytosolic fatty acid binding proteins and transport proteins chaperone fatty acids to the mitochondria to be metabolized for energy via $\beta$-oxidation., ${ }^{9,14}$ Dysfunctional mobilization often results in greater postprandial FFA plasma concentrations, which is a hallmark characteristic of individuals with type 2 diabetes.

\section{FATTY ACID ACCUMULATION IN SKELETAL MUSCLE TISSUE}

The mechanism by which fatty acids impair insulin-stimulated glucose oxidation in skeletal muscle has been described. ${ }^{3,15,16}$ Furthermore, studies have elucidated that the triglyceride content of muscle has a negative relationship with wholebody insulin sensitivity. Pan et al. ${ }^{17}$ performed hyperinsulinemic-euglycemic clamp studies on non-diabetic, overweight adult males to determine whole-body insulin sensitivity and then analyzed vastus lateralis biopsies for triglyceride content. Their results showed a negative correlation between the two. In order to further explain this relationship, in vivo studies ${ }^{18,19}$ have investigated how the source of triglycerides affects skeletal muscle insulin resistance by isolating extramyocellular and intramyocellular lipid fractions. ${ }^{18-21}$ Krssak et al. ${ }^{22}$ characterized the negative relationship of intramyocellular lipid fractions on whole body glucose uptake by demonstrating that intramyocellular stores are primarily responsible for increasing skeletal muscle insulin resistance. These discoveries helped subsequent investigators clarify the role of other cellular components by identifying and isolating receptors and intracellular intermediates associated with FFA accumulation and insulin resistance, with initial focus on glucose oxidation. Indeed, early research has shown that FFA concentrations and glucose metabolism impact each other, ${ }^{15,23,24}$ and more recent studies have begun to identify the intracellular axes and gene transcripts involved. ${ }^{8,9,14}$

FFA are transported from blood into skeletal muscle cells using fatty acid binding proteins (FABP) and fatty acid transport proteins (FATP). Collectively, there are a number of members of the FATP family that include FATP1, FATP4, and FATP $6 .{ }^{14}$ In addition to FFA transport, these FATP may have acyl-CoA synthetase enzymatic activity, which activates FFA for metabolism. ${ }^{9}$ FATP1 is the most prevalent transport protein expressed by skeletal muscle. ${ }^{14}$ It has a central role in fatty acid transport in T-tubules and it increases FFA 
oxidation in response to insulin stimulation. ${ }^{14}$ However, when FFA uptake occurs at a faster rate than FFA oxidation, it causes an accumulation of lipid intermediates that results in lipotoxic stress. ${ }^{25}$ Lipotoxicity results from excess intramyocellular buildup of triacylglycerol, diacylglycerol, longchain acyl CoA, and ceramides. The mechanism is not fully understood, but elevated lipid intermediates such as ceramides and diacylglycerol appear to impair insulin signaling in skeletal muscle. ${ }^{8}$ Ceramides are generated through a de novo pathway via condensation of palmitoyl CoA and serine. ${ }^{8}$ Ceramides are elevated in diabetic patients and inhibit a number of protein kinases, which are otherwise stimulated by insulin. They also likely activate the atypical protein kinase $\mathrm{C}$ isoforms within insulin-responsive tissues. ${ }^{13}$ This represents one potential mechanistic outcome whereby dysfunctional FFA mobilization and the resulting accumulation contribute to the development of skeletal muscle insulin resistance. In contrast, research has demonstrated that elevated triacylglycerol content in skeletal muscle is common among high-endurance athletes despite adequate hydrolysis of FFA. ${ }^{13}$ Individuals who undergo endurance training also have elevated ATGL expression in skeletal muscle cells, which is associated with increased oxidative capacity. ${ }^{13}$ Due to the increased energy demand of these athletes, increased lipolysis presumably helps fuel the requirements for their bodies' work output. Therefore, increased levels of circulating triacylglycerol in endurance athletes are understandable; however, further research is needed to identify what mechanisms are involved in maintaining insulin sensitivity in these individuals.

\section{HEPATIC LIPID METABOLISM}

The liver is a major regulator of lipid flux and plays a crucial role in maintaining FFA blood plasma concentrations. ${ }^{26}$ Hepatic FFA accumulation can occur as a consequence of decreased FFA oxidation, excessive FFA liberation from lipolyzed adipose triglycerides, inadequate triacylglycerol excretion, or hepatic de novo lipogenesis. ${ }^{26}$ Greater hepatic fat content from any of these mechanisms can contribute to the development of insulin resistance and type 2 diabetes. ${ }^{27}$ Most FFA taken up from circulation by the liver had entered the bloodstream after being mobilized from adipose tissue. ${ }^{26}$ The nuclear receptor peroxisome proliferator-activated receptor alpha (PPARa) senses the hepatic influx of circulating FFA and upregulates gene expression of fatty acid oxidative systems. ${ }^{28}$ The lab of JK Reddy ${ }^{28-31}$ identified this regulation mechanism by knocking out the genes for PPAR $\alpha$ and fatty acyl-CoA oxidase (ACOX) in mice. These mice were consequently unable to upregulate genes associated with fatty acid oxidation systems, and the subsequent increase in triglyceride synthesis contributed to the development of liver steatosis. ${ }^{28-31}$ Mitochondrial $\beta$-oxidation is a complex process that is regulated in part by enzymatic activity of carnitine palmitoyltransferase 1 and by concentrations of carnitine and malonyl-CoA. For $\beta$-oxidation to occur, intracellular FFA must first be activated into esters by acyl-CoA synthetase in order to enter the mitochondrial $\beta$-oxidation spiral. ${ }^{31}$ Downregulation of ACOX in the liver damages this transport system and thus decreases FFA oxidation within the cell. ${ }^{31}$ Regardless of the tissue, proper regulation and balance of FFA mobilization and oxidation is critical to maintain.

\section{FATTY ACID-INDUCED PANCREATIC B-CELL DYSFUNCTION}

Ex vivo studies have shown that prolonged exposure of rat pancreatic islets to elevated FFA concentrations decreases glucose-stimulated insulin secretion. $^{32,33}$ The impact of elevated circulating FFA concentrations on human $\beta$-cell function is less clear, as insulin secretion was increased after 6-hour FFA infusion but decreased after 24 hours in non-obese healthy individuals. ${ }^{34}$ When individuals were made chronically hyperglycemic, however, insulin secretion was increased by FFA infusion for 48 hours. ${ }^{35}$ Nevertheless, lipotoxicity is a potential source of $\beta$-cell injury in patients with type 2 diabetes. ${ }^{36}$ Deleterious effects on $\beta$-cells from prolonged exposure to high FFA concentrations are indicated by studies showing inhibition of insulin mRNA expression and increased ceramide production that led to nitric oxide-dependent cell death. ${ }^{36}$ Increased accumulation of islet amyloid after FFA exposure causes islet amyloidosis and inflammation. ${ }^{37}$ Amyloid deposition is associated with less islet volume due to a reduction in $\beta$-cell mass. ${ }^{38}$ It is important to note that some individual fatty acids such as palmitate can actually suppress $\beta$-cell dysfunction and demise, ${ }^{39,40}$ since these saturated fatty acids act as inhibitors of pyruvate carboxylase activity. ${ }^{41}$ It is clear that research has only begun to uncover how FFA concentrations impact $\beta$-cell function independent from fat mass. However, we have a better understanding of how these energy intermediates contribute to impaired insulin secretion and function in type 2 diabetes.

\section{CONCLUSION}

Dysregulation of fatty acid storage, mobilization, and metabolism is implicit in a number of metabolic 
diseases. It is becoming clear that the loss of free fatty acid homeostasis is at least partially independent of obesity, which furthers our understanding of the fatty acid cycle and its role in metabolic disease. However further research is warranted to elucidate the mechanistic details of these changes in fatty acid flux in order to address the growing global metabolic syndrome epidemic. Exploration of transcriptional modifications, understanding and isolating mechanisms underlying the "athlete phenomenon," and developing the basis for FFA therapies are fundamental steps in providing a better understanding of the interactive role that FFA flux plays in metabolic disease and improving outcomes in these individuals.

\section{ACKNOWLEDGMENTS}

This manuscript is based on research that was partially supported by the National Institute of General Medical Sciences Grant 1P20GM104320 (J. Zempleni, Director), the Nebraska Agricultural Experiment Station with funding from the Hatch Act (NEB-26-224) and Hatch Multistate Research capacity funding program (NEB-26-226, NEB-26225) through the USDA National Institute of Food and Agriculture. The Biomedical and Obesity Research Core (BORC) in the Nebraska Center for Prevention of Obesity Diseases (NPOD) receives partial support from NIH (NIGMS) COBRE IDeA award NIH 1P20GM104320. The contents of this publication are the sole responsibility of the authors and do not necessarily represent the official views of the NIH or NIGMS. The authors have no conflicts of interest to declare.

\section{REFERENCES}

1. Bastien M, Poirier P, Lemieux I, Despres JP. Overview of epidemiology and contribution of obesity to cardiovascular disease. Prog Cardiovasc Dis. 2014;56(4):369-81. 10.1016/j.pcad.2013.10.016.

2. Guilherme A, Virbasius JV, Puri V, Czech MP. Adipocyte dysfunctions linking obesity to insulin resistance and type 2 diabetes. Nat Rev Mol Cell Biol. 2008;9(5):367-77. https://doi.org/10.1038/nrm2391

3. Ebeling P, Koivisto VA. Non-esterified fatty acids regulate lipid and glucose oxidation and glycogen synthesis in healthy man. Diabetologia. 1994;37:202-9. https://doi. org/10.1007/s001250050094

4. Cnop M, Hannaert JC, Hoorens A, Eizirik DL, Pipeleers D. Inverse relationship between cytotoxicity of free fatty acids in pancreatic islet cells and cellular triglyceride accumulation. Diabetes. 2001;50:1771-7. https://doi.org/10.2337/ diabetes.50.8.1771

5. Zimmermann R, Strauss JG, Haemmerle G, Schoiswohl G, Birner-Gruenberger R, Riederer M, et al. Fat mobilization in adipose tissue is promoted by adipose triglyceride lipase. Science. 2004;306(5700):1383-6. https://doi.org/10.1126/ science. 1100747

6. Eckel RH, Grundy SM, Zimmet PZ. The metabolic syndrome. Lancet. 2005;365:1415-28. https://doi.org/10.1016/ s0140-6736(05)66378-7
7. Lass A, Zimmermann R, Oberer $M$, Zechner R. Lipolysis - a highly regulated multi-enzyme complex mediates the catabolism of cellular fat stores. Prog Lipid Res. 2011;50(1):14-27. https://doi.org/10.1016/j. plipres.2010.10.004

8. Ghosh N, Patel N, Jiang K, Watson JE, Cheng J, Chalfant CE, et al. Ceramide-activated protein phosphatase involvement in insulin resistance via akt, serine/arginine-rich protein 40 , and ribonucleic acid splicing in 16 skeletal muscle cells. Endocrinology. 2007;148(3):1359-66. 10.1210/en.2006-0750.

9. Jia Z, Pei Z, Maiguel D, Toomer CJ, Watkins PA. The fatty acid transport protein (fatp) family; very long chain acyl-coa synthetases or solute carries? J Mol Neurosci. 2007;33:25-31. https://doi.org/10.1007/s12031-007-0038-z

10. Peckett AJ, Wright DC, Riddell MC. The effects of glucocorticoids on adipose tissue lipid metabolism. Metabolism. 2011;60:1500-10. https://doi.org/10.1016/j. metabol.2011.06.012

11. Calder PC. Functional roles of fatty acids and their effects of human health. J Parenter Enteral Nutr. 2015;39(1 Suppl):18S-32S. https://doi. org/10.1177/0148607115595980

12. Stinkens R, Goossens GH, Jocken JW, Blaak EE. Targeting fatty acid metabolism to improve glucose metabolism. Obes Rev. 2015;16(9):715-57. https://doi.org/10.1111/obr.12298

13. Meex RC, Hoy AJ, Mason RM, Martin SD, McGee SL, Bruce CR, et al. Atgl-mediated triglyceride turnover and the regulation of mitochondrial capacity in skeletal muscle. Am J Physiol Endocrinol Metab. 2015;308(11):E96070. https://doi.org/10.1152/ajpendo.00598.2014

14. Hotamisligil GS, Bernlohr DA. Metabolic functions of fabps-mechanisms and therapeutic implications. Nat Rev Endocrinol. 2015;11(10):592-605. https://doi.org/10.1038/ nrendo.2015.122

15. Randle PJ, Garland PB, Hales CN, Newsholme EA. The glucose fatty-acid cycle its role in insulin senstivity and the metabolic disturbances of diabetes mellitus. Lancet. 1963;281(7285):785-9. https://doi.org/10.1016/ s0140-6736(63)91500-9

16. Felley CP, Felley EM, Van Melle GD, Frascarolo P, Jequier E, Felber JP. Impairment of glucose disposal by infusion of triglycerides in humans: Role of glycemia. Am J Physiol. 1989:747-52. https://doi.org/10.1152/ ajpendo.1989.256.6.e747

17. Pan DA, Lillioja S, Kriketos AD, Milner MR, Baur LA, Bogardus C, et al. Skeletal muscle triglyceride levels are inversely related to insulin action. Diabetes. 1997;46:9838. https://doi.org/10.2337/diabetes.46.6.983

18. Perseghin G, Scifo P, De Cobelli F, Pagliato E, Battezzati A, Arcelloni C, et al. Intramyocellular triglyceride content is a determinant of in vivo insulin resistance in humans a $1 \mathrm{~h}-13 \mathrm{c}$ nuclear magnetic resonance spectroscopy assessment in offspring of type 2 diabetic parents. Diabetes. 1999;48:1600-6. https://doi.org/10.2337/diabetes.48.8.1600

19. Boden G, Lebed B, Schatz M, Homko C, Lemieux S. Effects of acute changes of plasma free fatty acids on intramyocellular fat content and insulin resistance in healthy subjects. Diabetes. 2001;50:1612-7. https://doi.org/10.2337/ diabetes.50.7.1612

20. Jacob S, Machann J, Rett K, Brechtel K, Volk A, Renn W, et al. Association of increased intramyocellular lipid content with insulin resistance in lean nondiabetic offspring of type 2 diabetic subjects. Diabetes. 1999;48:1113-9. https:// doi.org/10.2337/diabetes.48.5.1113

21. Bachmann OP, Dahl DB, Brechtel K, Machann J, Haap M, Maier T, et al. Effects of intravenous and dietary lipid challenge on intramyocellular lipid content and the relation with insulin sensitvity in humans. Diabetes. 2001;50:257984. https://doi.org/10.2337/diabetes.50.11.2579

22. Krssak M, Falk Petersen K, Dresner A, DiPietro L, Vogel SM, Rothman DL, et al. Intramyocellular lipid concentrations are correlated with insulin sensitivity in humans a $1 \mathrm{~h}$ nmr spectroscopy study. Diabetologia. 1999;42:113-6. https://doi.org/10.1007/s001250051123 
23. Dole VP. A relation between non-esterified fatty acids in plasma and the metabolism of glucose. J Clin Invest. 1956;35:150-4. https://doi.org/10.1172/jci103259

24. Penicaud L, Ferre P, Kande J, Leturque A, Issad T, Girard J. Effect of anesthesia on glucose production and utilization in rats. Am J Physiol. 1987;252:365-9. https://doi. org/10.1152/ajpendo.1987.252.3.e365

25. Corpeleijn E, Saris WH, Blaak EE. Metabolic flexibility in the development of insulin resistance and type 2 diabetes: Effects of lifestyle. Obes Rev. 2009;10(2):178-93. https:// doi.org/10.1111/j.1467-789x.2008.00544.x

26. Bugianesi E, McCullough AJ, Marchesini G. Insulin resistance: A metabolic pathway to chronic liver disease. Hepatology. 2005;42(5):987-1000. https://doi.org/10.1002/ hep. 20920

27. Yki-Jarvinen H. Liver fat in the pathogenesis of insulin resistance and type 2 diabetes. Dig Dis. 2010;28(1):203-9. $10.1159 / 000282087$.

28. Yu S, Rao S, Reddy JK. Peroxisome proliferator-activated receptors, fatty acid oxidation, steatohepatitis and hepatocarcinogenesis. Current Molecular Medicine. 2003;3(6):561-72. https://doi. org/10.2174/1566524033479537

29. Hashimoto T, Fujita T, Usuda N, Cook W, Qi C, Peters JM, et al. Peroxisomal and mitochondrial fatty acid beta-oxidation in mice nullizygous for both peroxisome proliferator-activated receptor alpha and peroxisomal fatty acyl-coa oxidase. Genotype correlation with fatty liver phenotype. J Biol Chem. 1999;274(27):19228-36.

30. Hashimoto T, Cook WS, Qi C, Yeldandi AV, Reddy JK, Rao MS. Defect in peroxisome proliferator-activated receptor alpha-inducible fatty acid oxidation determines the severity of hepatic steatosis in response to fasting. J Biol Chem. 2000;275(37):28918-28. 10.1074/jbc.M910350199.

31. Reddy JK. Nonalcoholic steatosis and steatohepatitis iii. Peroxisomal. Am J Physiol Gastrointest Liver Physiol. 2001;281:G1333- G9. http://dx.doi.org/10.1152/ ajpgi.2001.281.6.g1333.

32. Sako Y, Grill VE. A 48-hour lipid infusion in the rat time-dependently inhibits glucose-induced insulin secretion and $\mathrm{b}$ cell oxidation through a process llikely coupled to fatty acid oxidation. Endocrinology. 1990;127(4):15809. https://doi.org/10.1210/endo-127-4-1580

33. Polonsky KS. The b-cell in diabetes: From molecular genetics to clinical research. Am Diabetes Assoc. 1994;44:70517. https://doi.org/10.2337/diab.44.6.705
34. Paolisso G, Gambardella A, Amato L, Tortoriello R, D’Amore A, Varricchio M, et al. Opposite effects of shortand long-term fatty acid infusion on insulin secretion in healthy subjects. Diabetologia. 1995;38:1295-9. https://doi. org/10.1007/s001250050426

35. Boden G, Chen X, Rosner J, Barton M. Effects of a 48-h fat infusion on insulin secretion and glucose utilization. Diabetes. 1995;44:1239-42. https://doi.org/10.2337/ diab.44.10.1239

36. Prentki M, Nolan CJ. Islet beta cell failure in type 2 diabetes. J Clin Invest. 2006;116(7):1802-12. https://doi. org/10.1172/jci29103

37. Meier DT, Morcos M, Samarasekera T, Zraika S, Hull RL, Kahn SE. Islet amyloid formation is an important determinant for inducing islet inflammation in high-fat-fed human iapp transgenic mice. Diabetologia. 2014;57(9):1884-8. 10.1007/s00125-014-3304-y.

38. Westermark PJ, Virchows AA. Fine structure of islets of langerhans in insular amyloidosis. 1973;359(1):1-18. https://doi.org/10.1007/bf00549079

39. Jung IR, Choi SE, Jung JG, Lee SA, Han SJ, Kim HJ, et al. Involvement of iron depletion in palmitate-induced lipotoxicity of beta cells. Mol Cell Endocrinol. 2015;407:74-84. 10.1016/j.mce.2015.03.007.

40. Roomp K, Kristinsson H, Schvartz D, Ubhayasekera K, Sargsyan E, Manukyan L, et al. Combined lipidomic and proteomic analysis of isolated human islets exposed to palmitate reveals time-dependent changes in insulin secretion and lipid metabolism. PLOS ONE. 2017;12(4):e0176391. 10.1371/journal.pone.0176391.

41. Lee JH, Jung IR, Choi SE, Lee SM, Lee SJ, Han SJ, et al. Toxicity generated through inhibition of pyruvate carboxylase and carnitine palmitoyl transferase- 1 is similar to high glucose/palmitate-induced glucolipotoxicity in ins-1 beta cells. Mol Cell Endocrinol. 2014;383(1-2):48-59. 10.1016/j.mce.2013.12.002.

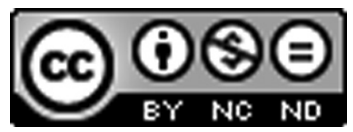

This work is licensed under a Creative Commons Attribution-Non Commercial-No Derivatives 4.0 International License. To view a copy of this license, visit http://creativecommons.org/licenses/by-nc-nd/4.0/ 